\title{
Suicidal Behavior among Adolescents with Borderline Personality Disorder
}

\author{
Zainab Hamid $^{1 *}$, Shawkat Ahmad Shah ${ }^{2}$
}

\section{ABSTRACT}

The present study is based on a systematic research review. Systematic review is to identify, evaluate, and summaries the findings of all relevant studies. Systematic reviews represent one of the most important forms of research evidences upon which clinicians, their patients and policy makers rely when making decisions. The review of literature is significant constituent of the research process and should be carried out in an organized manner. It involves a systematic identification, location and analysis of documents containing information related to the research problem. The reason of reviewing literature is to determine what has already done by the scientific community related to the research problem and to gain a notion regarding different aspects of the subject matter understudy. The major objective of the current study is to conduct a systematic review on Suicidal behavior in borderline Personality disorder among adolescents. To accomplish this objective, it was very important to collect the literature on; (A). Adolescents (B). Suicidal behavior. (C). Borderline personality disorder among adolescents.

Keywords: Adolescents, Suicidal behavior and Borderline personality disorder.

At no other time in history has the journey between childhood and adulthood been more challenging. It is largely assumed that adolescence is a period of change and turmoil. This might be the reason that it is confusing for clinicians to consider diagnosing a personality disorder during a time of identity, questioning and consolidation. Borderline personality disorder (BPD) is estimated to affect between $0.9 \%$ and $3 \%$ of teenagers in the community, (Chanen, McCutcheon, Jovev, Jackson, \& McGorry, 2007) which is equivalent to the prevalence in adults (Lenzenweger, Lane, Loranger, \& Kessler, 2007). The data confirm that BPD usually becomes clinically apparent during adolescence, peaks in young adulthood, and attenuates across the remainder of the life course (Chanen, \& Kaess, 2012). Several studies have shown that specific features of BPD, such as self-harm, impulsivity and emotional dysregulation, present during

\footnotetext{
${ }^{1}$ Research Scholar, PG Department Of Psychology, University Of Kashmir.

${ }^{2}$ Associate Professor, PG Department Of Psychology, University Of Kashmir.

*Responding Author

(C) 2016 I Z Hamid, S Shah; licensee IJIP. This is an Open Access Research distributed under the terms of the Creative Commons Attribution License (http://creativecommons.org/licenses/by/2.0), which permits unrestricted use, distribution, and reproduction in any Medium, provided the original work is properly cited.
} 
childhood or adolescence, are predictive of BPD diagnoses in adulthood (Siever, Torgersen, Gunderson, Livesley, \& Kendler, 2002; Zanarini, Frankenburg, Ridolf, Jager-Hyman, Hennen, \&Gunderson, 2002). Among these, impulsivity in particular is regarded as a core feature of BPD ( Lieb, Zanarini, Schmahl, Linehan, Bohus, 2004; Links, Heslegrave, \& van Reekum, 1999). Impulsivity is associated with factors contributing to the severity of the disorder, such as suicidal/self-harming behaviors or increased risk for substance abuse (Moeller, Barratt, Dougherty, Schmitz, \& Swann, 2001; Winstanley, Eagle, \& Robbins, 2006). Brent.et al (1994) assessed the association between personality disorders, personality traits, impulsive violence, and suicide. Result of the study revealed that Personality disorders and the tendency to engage in impulsive violence are critical risk factors for completed suicide.

\section{LITERATURE ON SUICIDE IN ADOLESCENTS}

Suicide is one of the leading causes of death worldwide, with global average rate of16.7/100,000 persons per year (World Health Organization, 2007). Suicide is the second leading cause of death among young people aged 15-29 in Europe, following unintentional injuries (Blum \& NelsonMmari, 2004). Ninety per cent of people who commit suicide have been diagnosed with a serious mental illness; psychiatric disorders and substance abuse problems have been consistently identified as risk factors for suicide and suicidal ideation (Centre for Applied Research in Mental Health and Addiction, 2007; Jacobs, 2007). Suicide rates vary markedly by age, gender and ethnicity. Adolescence and early adulthood are the times of greatest risk for the onset of suicidal ideation and behavior (Nock et al., 2008).Suicide is defined as the act of intentionally ending one's own life (Silverman, et al., 2007). Suicide behavior that does not result in death includes: suicide ideation (thoughts of engaging in behavior to end one's life); suicide plan (forming a specific method through which one intends to die); and suicide attempt (engaging in potentially injurious behavior with at least some intent to die). Although these behaviors represent a continuum of severity, from ideation through attempts to fatal act, in many cases they occur independently. For adolescents aged 12 to 17 years, lifetime prevalence of suicide ideation ranges from 19.8 to $24.0 \%$, and for suicide attempts from 3.1 to $8.8 \%$. The 12 - month rates are similar, ranging from 15.0 to $29.0 \%$ for ideation, 12.6 to $19.0 \%$ for plans, and 7.3 to $10.6 \%$ for suicide Attempts.

There are some risk factors that may be particularly influential in determining suicide risk among adolescents and young adults. Impulsivity may be particularly important in adolescent suicide (McGirr et al., 2008), but only certain facets may be closely related to suicide, specifically, the tendency to act without much thinking or deliberation (Yen et al., 2009). For boys, those who at age 8 are frequent victims of bullying and those who bully are at increased risk for suicide in adolescence (although the effect is not found when controlling for conduct problems and depression symptoms); for girls, being a victim of bullying is associated with increased suicide risk even when controlling for conduct and depressive symptoms (Klomek et al., 2008, 2009). Parental criticism also is associated with adolescent self-injurious behavior (Wedig \& Nock, 2007). Miller (2007) mentioned that interpersonal conflicts and separations are the most common 
precipitants of adolescent suicide. He pointed out breakups of romantic relationships, disciplinary crisis or legal problems, humiliation and arguments, which are stressors identified in attempted and completed suicides of youth (Miller, Rathus, \& Linehan, 2007). Horesh, Orbach, Gothelf , Efrati , \& Apter (2003) conducted a study to examined that some forms of suicidal behavior among adolescents are related to helplessness and depression, whereas others are related to anger and impulsivity. In the subjects with Borderline Personality Disorder, Impulsiveness and aggression correlated significantly and positively with suicidal behavior. In the subjects with major depressive disorder (MDD), no such correlations were seen. In both diagnostic groups, depression and hopelessness correlated positively and significantly with suicidal behavior. Anger did not correlate with suicidal behavior in either of the groups.

\section{LITERATURE ON BORDERLINE PERSONALITY DISORDER IN ADOLESCENTS}

Borderline personality disorder (BPD) is an impairing mental disorder that concerns $1-2 \%$ of the general population. Although BPD is usually diagnosed in adults, symptoms of BPD can often be traced back to childhood (Miller, Muehlenkamp, \& Jacobson, 2008). It is characterized by a pervasive pattern of instability in affect regulation, impulse control, interpersonal relationships, and self-image ( Lieb, Zanarini, Schmahl, Linehan, \&Bohus, 2004). Several studies have shown that individual with BPD have more difficulty in their adaptive functioning and interpersonal behavior (Kraus\& Reynolds, 2001). A recent study investigating affective experience and interpersonal behavior of individuals with BPD (Russell, Moskowitz, Zuroff, Sookman, \& Paris, 2007) found elevated Levels of submissive and quarrelsome behavior, reduced levels of dominant behavior, and overall more extreme behavior relative to non-clinical control participants. Other studies also point to emotion deregulation, or poor emotion management in BPD (Bland, Williams, Scharer, \& Manning, 2004; Zlotnick et al., 2002). Studies indicated that individuals with BPD also characterize their interpersonal behavior as overly nurturing, exploitable, and socially avoidant. (Gunderson, 2003). Choudhary \&Thapa, (2014) found defining characteristics of BPD such as substance abuse, suicidality, academic failure, social dysfunction, dependency on others and personal distress was identified. . In the study by Becker et al(2000) anger was found to be the best exclusion criterion for BPD in adolescents and the abandonment fears were found to be the best inclusion criteria for adolescents(Becker, Grilo, Edell,\& McGlashan ,2002). A study done by Bounoua et al., (2015) to explored the impact of anxiety sensitivity in the development of BPD symptoms in a group of adolescents. Results suggest a significant indirect effect of emotional abuse on BPD symptoms via anxiety sensitivity. These findings suggest that, among adolescents, Anxiety Sensitivity may serve as an important contributor to the development of BPD symptoms. Thatcher et al.(2005) followed 355 adolescents from clinical and community sources from average age 16 to average age 22 and found that adolescent alcohol use disorder was significantly associated with increased borderline personality disorder symptoms in young adulthood.

Over the past several decades, research has focused increasingly on developmental antecedents to psychological disorders that were previously assumed to emerge only in adulthood. This 
change in notion follows from the recognition that complex transactions between biological vulnerabilities and psychosocial risk factors shape emotional and behavioral development beginning at conception. The results of a large study done in UK suggest that inherited and environmental risk factors make independent and interactive contributions to borderline etiology, supporting the current models of diathesis-stress theories, pointing to an interaction between genetic vulnerability and harsh treatment in the family (Belsky.,et.al, 2012).

Factors identified as predictors or risk factors for BPD in adolescents include history of disrupted attachment, maternal neglect, maternal rejection, grossly inappropriate parental behavior, number of mother and father surrogates, physical abuse, sexual abuse, and parental loss (Ludolph, Westen, Misle , Jackson, Wixom , \&Wis, 1990; Chanen, \&Kaess, 2012). Borderline characteristics were more frequent in children who had exhibited poor cognitive function, impulsivity, and more behavioral and emotional problems, but also in those who were exposed to harsh treatment. These all become higher risk factors in the presence of each other and also when there is a family history of psychiatric illness (Belsky, Caspi , \&Arsenault , et al., 2012). Studies add low socioeconomic status to childhood abuse and neglect, and problematic family environment, as significant risk factors for personality pathology, especially BPD (Chanen \&Kaess, 2012).It is also supposed that BPD results from the interaction between temperament and parenting failures . A study done by Agrawal et al. (2004) suggested that there was a strong association between insecure forms of attachment and borderline personality disorder. Linehan(2007) described that invalidating environment may also interfere with attachment and the learning of emotion regulation strategies. The temperamental factors might be emotional reactivity or difficulty being alleviated, which are challenging for any parent, and especially for those who share these genetic predispositions. Many Studies revealed that there is a strong relationship between BPD and insecure (mainly preoccupied) attachment (Agrawal, Gunderson, Holmes \& Lyons-Ruth,m 2004; Kobak, Zajak , \&Smith, 2009). Research showed that childhood emotional, physical, and supervision neglect may play a role in the etiology of some Personality Disorders (Johnson, Smailes, Cohen, Brown, \&Bernstein, 2000).

\section{LITERATURE ON RELATIONSHIP BETWEEN SUICIDAL BEHAVIOR AND BORDERLINE PERSONALITY DISORDER}

Young people's affinity to highly impulsive and self-damaging behavior places them at risk for adverse health outcomes. Among adolescents with BPD, "self-harm and suicidal behavior" is the most frequently met BPD criterion. This differs from adulthood, when rates of self-harm and suicidal behavior decline (Zanarini, Frankenburg, Reich, Fitzmaurice, Weinberg, \& Gunderson, 2008). Borderline personality disorder (BPD) is a common and severe mental disorder that is associated with severe functional impairment and a high suicide rate. Patients with BPD represent 9\% to 33\% of all suicides,( Kullgren , Renberg , \& Jacobsson ,1986; Runeson, \& Beskow ,1991) and the lifetime suicide rate for BPD is estimated to be 8\% (Pompili , Girardi , Ruberto ,\& Tatarelli,2005). Five out of eight patients reported suicidal attempts or threats. Zanarini et al., (2006) reported that $32.8 \%$ of BPD self-injurers began before age 12, as 30.2\% 
began as adolescents and 37\% began as adults (Zanarini, Frankenburg, Ridolfi, Jager-Hyman, Hennen, \& Gunderson, 2006). Pompili, Girardi, Ruberto, \& Tatarelli, 2005 suggesting that the early years after acute clinical care might be the period of highest risk. However, the study with the longest duration of follow-up (27 years) suggests that suicide occurs later in the course of BPD (Paris \& Zweig-Frank, 2001). Borderline patients at greatest risk for suicidal behavior include those with prior attempts, comorbid major depressive disorder, or a substance use disorder. Comorbidity with major depression serves to increase both the number and seriousness of the suicide attempts. Hopelessness and impulsivity independently increase the risk of suicidal behavior, as does a turbulent early life and the presence of antisocial traits (Black, Blum, Pfohl, \& Hale, 2004). A study had done byYen, Gagnon, \& Spirito, (2013) to examined differences between suicidal adolescents with and without BPD on history and characteristics of suicidal behavior, Axis I comorbidity, affect regulation, and aggression. BPD participants were more likely to have a past history of suicide attempts and to have been admitted due to a suicide attempt (vs. suicidal ideation). The Results demonstrate that compared to other acutely suicidal adolescents, the clinical profile of BPD participants is unique and suggests an increased risk for suicidal behaviors. Another study conducted by Oumaya , Friedman, Pham, Abou Abdallah, Guelfi, \& Rouillon, (2008) to examined the relationships between self-mutilations, suicide and related therapeutic approach. Result showed that Borderline patients with history of selfmutilation behavior have about twice the rate of suicide than those without.

\section{CONCLUSION}

The above data suggest that Borderline Personality Disorder (BPD) is among the most functionally disabling of all mental disorders. Suicidal behavior is frequent in patients with borderline personality disorder (BPD); at least three-quarters of these patients attempt suicide and approximately $10 \%$ eventually complete suicide. Borderline patients at greatest risk for suicidal behavior include those with prior attempts, co-morbid major depressive disorder, or a substance use disorder. As BPD is frequently complicated by suicidal behavior, clinicians must avoid the mistake of thinking that a pattern of repeated attempts indicates little desire to die. Clinicians have an important role in preventing suicide attempts and completed suicides by understanding the risk factors. In this review, diverse literatures are reviewed that can inform understanding of the ontogenesis of borderline pathology, and to guide future research with atrisk children and adolescents. One probable pathway is identified that leads to borderline personality disorder; it begins with early vulnerability, expressed initially as impulsivity and followed by heightened emotional sensitivity. These vulnerabilities are potentiated across development by environmental risk factors that give rise to more extreme emotional, behavioral, and cognitive dysregulation.

\section{REFERENCES:}

Agrawal, H. R., Gunderson, J., Holmes, B.M., \& Lyons-Ruth, K. (2004).Attachment studies with borderline patients. A review. Harvard Review of Psychiatry, 12, 94-104. 
Beatson, J., Rao, S., \& Watson, C. (2010). Borderline personality disorder: towards effective treatment. Fitzroy: Victorian Medical Post Graduate Foundation.

Becker, D.F., Grilo, C.M., Edell, W.S., \&McGlashan, T.H. (2002). Diagnostic efficiency of borderline personality disorder criteria in hospitalized adolescents: comparison with hospitalized adults. Am J Psychiatry, 159, 2042-2047.

Belsky, D.W., Caspi, A., Arsenault L., et al. (2012). Etiological features of borderline personality related characteristics in a birth cohort of 12-year-old children. Dev Psychopatho, 24, 251-265.

Black,D.W., Blum.N., Pfohl,B., \& Hale.N.(2004). Suicidal Behavior in Borderline Personality Disorder: Prevalence, Risk Factors, Prediction, and Prevention. Journal of Personality Disorders, 18(3), 226-239.

Bland, A. R., Williams, C. A., Scharer, K., \& Manning, S. (2004).Emotion processing in borderline personality disorders. Issues Mental Health Nursing, 25, 655-667.

Bounoua,N., Felton, J. F., Long, K., Stadnik,R. D., Loya,J. M., Pherson, L. M ., \&Lejuez,C W.(2015).Childhood emotional abuse and borderline personality features: The role of anxiety sensitivity among adolescents. Personality and Mental Health. , 9(2), 87-95.

Brent,D.A., et al. (1994). Personality Disorder, Personality Traits, Impulsive Violence, and Completed Suicide in Adolescents Journal of the American Academy of Child \& Adolescent Psychiatry, 33(8), 1080-1086.

Chanen, A.M., Cutcheon, L.K., Jovev, M., Jackson, H.J.,\& McGorry, P.D(2007). Prevention and early intervention for borderline personality disorder. Med J Aust; 187:18-21.

Chanen, A. M., \& Cutcheon, L.M. (2013) Prevention and early intervention for borderline personality disorder: current status and recent evidence. The British Journal of Psychiatry , 202 (54) 24-29.

Chanen, A.M, \& Kaess, M. (2012). Developmental pathways to borderline personality disorder. Curr Psychiatry Rep. 14(1):45-53.

Choudhary,S \&Thapa,K. (2014) Clinical Profile of Borderline Personality Disorder in North India. Psychol Stud, 59(4):374-382

Crowell, S. E., Beauchaine, T. P., Linehan, M.M. (2009). A biosocial developmental model of borderline personality: Elaborating and extending linehan's theory. Psychological Bulletin, 135(3), 495-510.

Drew, W., Pamela, L., Barbara, M., Stephen, R.\& Judith, B .(1990) .Physical and sexual abuse in adolescent girls with borderline personality disorder. American Journal of Orthopsychiatry, 60(1), 55-66.

Fonagy, P., \& Bateman, A. (2008). The development of BPD - a mentalizing model. J Personal Disord, 22, 4-21.

Gunderson, J. G. (2003). Borderline personality disorder: A clinical guide. Washington: American Psychiatric Press.

Horesh, N., Orbach, I., Gothelf ,D., Efrati, M., \& Apter. A (2003).Comparison of the suicidal behavior of adolescent inpatients with borderline personality disorder and major depression. The Journal of Nervous and Mental Disease , 191(9),582-588. 
Johnson, J.G., Smailes, E.M., Cohen, P., Brown, J ., \& Bernstein,D.P.(2000). Associations Between Four Types of Childhood Neglect and Personality Disorder Symptoms During Adolescence and Early Adulthood: Findings of a Community-Based Longitudinal Study. Journal of Personality Disorders, 14(2), 171-187.

Kaess, M., Brunner, R., \& Chanen, A. (2014). Borderline Personality Disorder in Adolescence. American Academy of Pediatrics.134 (4).

Kobak, R., Zajak, K., \& Smith, C. (2009). Adolescent attachment and trajectories of hostileimpulsive behavior: implications for the development of personality disorders. Dev Psychopathol, 21, 839-851.

Kraus, G., \& Reynolds, D. J. (2001). The "A-B-C's" of the cluster B's: Identifying,understanding, and treating cluster B personality disorders.Clinical Psychology Review, 21(3), 345-373.

Kullgren .G., Renberg. E., \& Jacobsson. L. (1986). An empirical study of borderline personality disorder and psychiatric suicides. J Nerv Ment Dis, 174(6), 328-331.

Larrivée, M.P. (2013).Borderline personality disorder in adolescents: the- He-Who must- not be-named of psychiatry. Dialogues Clin Neurosci, 15(2): 171-179.

Lenzenweger, M.F., Lane, M.C., Loranger, A.W., \& Kessler, R.C. (2007). DSM-IV personality disorders in the national comorbidity survey replication. Biol Psychiatry, ,62, 553-564.

Lieb, K., Zanarini, M.C., Schmahl, C., Linehan, M.M., \& Bohus, M. (2004). Borderline personality disorder. Lancet, 364(9432),453-461.

Links , P.S., Heslegrave, R., van Reekum, R.(1999). Impulsivity: core aspect of borderline personality disorder. J Pers Disord, 13(1),1-9.

Ludolph, P.S., Westen, D., Misle, B., Jackson, A., Wixom, J.,\& Wiss, F.C.(1990). The borderline diagnosis in adolescents: symptoms and developmental history. Am J Psychiatry,147, 470-476.

Miller, A. L., Rathus, J. H., \& Linehan M.M.(2007). Dialectical behavior therapy: treatment stages, primary targets, and strategies. In: Dialectical Behavior Therapy with Suicidal Adolescents. New York NY; London, UK: The Guilford Press ,38-70.

Miller, A. L., Rathus, J. H., \& Linehan M.M. (2007). Suicidal behaviors in adolescents. In: Dialectical Behavior Therapy with Suicidal Adolescents. New York, NY; London, UK: The Guilford Press ,7-27.

Miller, A.L., Muehlenkamp, J.J., \& Jacobson, C.M. (2008). Fact or fiction: diagnosing borderline personality disorder in adolescents. Clin Psychol Rev , 28,(6), 969-981.

Moeller, F.G., Barratt, E.S., Dougherty, D.M., Schmitz, J.M.,\& Swann, A.C(2001): Psychiatric aspects of impulsivity.Am J Psychiatry , 158(11):1783-1793.

Oumaya, M., Friedman,S., Pham, A.,\& Abou Abdallah, T., Guelfi, J.D.,\& Rouillon .F.(2008). Borderline personality disorder, self-mutilation and suicide: literature review, j.encep , 34(5),4528.

Paris, J., \&Zweig-Frank, H .(2001). A 27-year follow-up of patients with borderline personality disorder. Compr Psychiatry,42 (6),482-487.

Perry, J. C. (1993). Longitudinal studies of personality disorders. Journal of Personality Disorders, 7, 63-85. 
Pompili, M., Girardi, P., Ruberto , A., \& Tatarelli, R. (2005). Suicide in borderline personality disorder: a meta-analysis. Nord J Psychiatry, 2005,59 (5),319-324.

Runeson .B., \& Beskow, J. (1991). Borderline personality disorder in young Swedish suicides. J Nerv Ment Dis, 179(3), 153-156.

Russell, J., Moskowitz, D. S., Zuroff, D. C., Sookman, D., \& Paris, J. (2007). Stability and variability of affective experience and interpersonal behavior in Borderline Personality Disorder. Journal of Abnormal Psychology, 116, 578-588.

Siever, L.J., Torgersen, S., Gunderson, J.G., Livesley, W.J., \& Kendler, K.S. (2002).The borderline diagnosis III: identifying endophenotypes for genetic studies. Biol Psychiatry , 51(12), 964-968.

Winstanley, C.A., Eagle, D.M., \& Robbins, T.W. (2006). Behavioral models of impulsivity in relation to ADHD: translation between clinical and preclinical studies.Clin Psychol, 26(4), 379-395.

Yen,S., Gagnon, K., \& Spirito, A. (2013). Borderline Personality Disorder in Suicidal Adolescents. Personal Ment Health, 7(2), 89-101.

Zanarini ,M.C., Frankenburg, F.R., Reich, D.B., Fitzmaurice, G., Weinberg, I., \& Gunderson, J.G.(2008). The 10-year course of physically self-destructive acts reported by borderline patients and axis II comparison subjects. Acta Psychiatr Scand, 117(3).

Zanarini, M.C., Frankenburg, F.R., Ridolfi, M.E., Jager-Hyman, S., Hennen, J.,\& Gunderson J.G.(2006).Reported childhood onset of self-mutilation among borderline patients. J Pers Disord , 20(1), 9-15.

Silverman, M. M., Berman, A. L., Sanddal, N. D., O'Carroll P, W., \& Joiner, T. E. (2007). Rebuilding the tower of Babel: a revised nomenclature for the study of suicide and suicidal behaviors. Part 1: Background, rationale, and methodology.Suicide \& Life Threatening Behavior, 37(3), 248-263.

Silverman, M. M., Berman, A. L., Sanddal, N. D., O'Carroll P, W., \& Joiner, T. E.(2007). Rebuilding the tower of Babel: a revised nomenclature for the study of suicide and suicidal behaviors. Part 2: Suicide-related ideations, communications,and behaviors. Suicide \& Life Threatening Behavior, 37(3), 264-277.

Blum, R. W., \& Nelson-Mmari, K. (2004). The health of young people in a global context. Journal of Adolescent Health, 35, 402-418.

Nock, M. K., Borges, G., Bromet, E. J., Cha, C. B., Kessler, R. C., \& Lee, S. (2008).Suicide and suicidal behavior. Epidemiologic Reviews, 30, 133-154.

McGirr, A., Renaud, J., Bureau, A., Seguin, M., Lesage, A., \& Turecki, G. (2008).Impulsiveaggressive behaviours and completed suicide across the life cycle: apredisposition for younger age of suicide. Psychological Medicine, 38(3), 407-417.

Yen, S., Shea, M. T., Sanislow, C. A., Skodol, A. E., Grilo, C. M., Edelen, M. O., et al. (2009). Personality traits as prospective predictors of suicide attempts. Acta Psychiatrica Scandinavica

World Health Organization (2007). Suicide prevention (SUPRE), fromhttp://www.who.int/mental_health/prevention/suicide/suicideprevent/en/. 
Wannan, G. \& Fombonne, E. (1998). Gender differences in rates and correlates of suicidal behavior among child psychiatric outpatients. Journal of Adolescence,21(4), 371-381.

Wedig, M. M., \& Nock, M. K. (2007). Parental expressed emotion and adolescent selfinjury. Journal of the American Academy of Child \& Adolescent Psychiatry, 46(9), 1171-1178.

Klomek, A. B., Marrocco, F., Kleinman, M., Schonfeld, I. S., \& Gould, M. S. (2008). Peer victimization, depression, and suicidality in adolescents. Suicide \& Life Threatening Behavior, 38(2), 166-180.

Klomek, A. B., Sourander, A., Niemela, S., Kumpulainen, K., Piha, J., Tamminen, T., et al. (2009). Childhood bullying behaviors as a risk for suicide attempts and completed suicides: a population-based birth cohort study. Journal of the American Academy of Child \& Adolescent Psychiatry, 48(3), 254-261.

Jacobs, D. (2007). Suicide Assessment. University of Michigan Depression Centre Colloquium Series. [PowerPoint presentation]. Retrieved from www.stopasuicide.org/professional.aspx.

Centre for Applied Research in Mental Health and Addiction. (2007).Working with the Client Who is Suicidal: A Tool for Adult Mental Health and Addiction Services. British Columbia Ministry of Health. Retrieved from www.carmha.ca

Thatcher, D.L., Cornelius, J.R., \& Clark, D.B(2005). Adolescent alcohol use disorders predict adult borderline personality. Addict Behav ;30:1709-1724. 